\title{
Pseudomonas infection in a postoperative foot wound
}

\author{
Mesut Mutluoglu MD, Gunalp Uzun MD
}
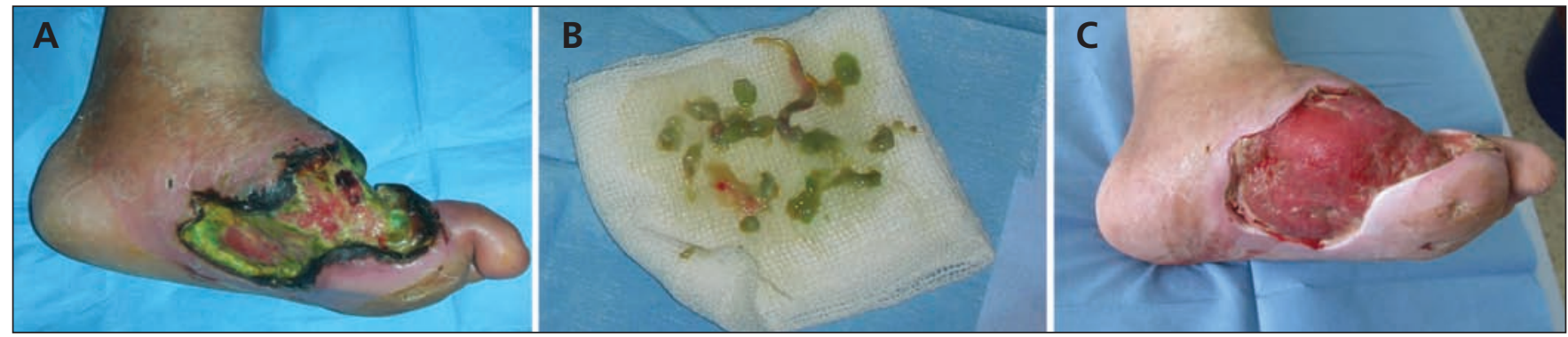

Figure 1: (A) Green discoloration of a postoperative wound in a 57-year-old man with type 2 diabetes mellitus three weeks after amputation of a gangrenous big toe. (B) Green debris removed from the wound. (C) The wound is ready for grafting after six months of comprehensive wound care and antimicrobial treatment.

$\mathrm{A}$ 57-year-old man with type 2 diabetes mellitus of 20 years' duration presented three weeks after amputation of a gangrenous big toe with a large nonhealing, infected foot wound at the surgical site. The wound had increased in size within days and had become infected despite regular professional foot care. He had been prescribed oral amoxicillin-clavulanate for 10 days, followed by oral ciprofloxacin for another 10 days. The patient took insulin twice daily but had poor diabetes control, with a hemoglobin $\mathrm{A}_{1 \mathrm{C}}$ level of $8.5 \%$ (normal $3.3 \%-6.4 \%$ ). He had no previous ulceration and his only known comorbidity was well-controlled hypertension.

On examination, his peripheral pulses were weak and he had a severe loss of foot sensation bilaterally. The wound base had substantial green discoloration (Figure 1A, B) associated with a sweet smell presumptive of Pseudomonas aeruginosa infection. Quantitative deep tissue and bone cultures grew $P$. aeruginosa and methicillinresistant Staphylococcus aureus strains. The green discoloration disappeared after one month of parenteral antibiotics, including vancomycin and imipenem, and topical silver-impregnated dressings. Antimicrobial treatment continued until wound cultures grew no more pathogens. Subsequently, the wound became appropriate for skin grafting six months after admission (Figure
1C), and the patient was able to walk three weeks after the procedure. Nine months later, he had a small $(3 \times 2 \mathrm{~cm})$ noninfected wound overlying the graft and was still ambulatory.

Patients with poorly controlled diabetes complicated by peripheral neuropathy or peripheral arterial disease are at increased risk for postoperative infection. ${ }^{1,2} S$. aureus is the most frequently cultured micro-organism, and $P$. aeruginosa is among the most prevalent gram-negative organisms isolated from diabetic foot wounds. ${ }^{3}$ The classic occurrence of green discoloration results from several pigments secreted by $P$. aeruginosa. Because $P$. aeruginosa has a predilection for growth in moist environments, comprehensive wound care avoiding soaking and maceration is essential, along with intensive antimicrobial therapy. ${ }^{4}$

\section{References}

1. Wukich DK, Lowery NJ, McMillen RL, et al. Postoperative infection rates in foot and ankle surgery: a comparison of patients with and without diabetes mellitus. J Bone Joint Surg Am 2010;92:287-95

2. Lipsky BA, Berendt AR, Deery HG, et al.; Infectious Diseases Society of America. Diagnosis and treatment of diabetic foot infections. Clin Infect Dis 2004;39:885-910.

3. Lipsky BA. Infectious problems of the foot in diabetic patients. In: Bowker JH, Pfeifer MA, editors. Levin and O'Neal's the diabetic foot. 6th ed. St. Louis (MO): CV Mosby; 2001. p. 467-80.

4. Frykberg RG, Zgonis T, Armstrong DG, et al.; American College of Foot and Ankle Surgeons. Diabetic foot disorders. A clinical practice guideline (2006 revision). J Foot Ankle Surg 2006;45(Suppl):S1-66.
Competing interests: None declared.

This article has been peer reviewed.

Affiliations: From the Department of Underwater and Hyperbaric Medicine, Gulhane Askeri Tip

Akademisi (GATA)

Haydarpasa Teaching Hospital, Istanbul, Turkey

Correspondence to:

Dr. Mesut Mutluoglu, drmutluoglu@gmail.com

CMAJ 2011. DOI:10.1503 /cmaj.100556 